\title{
Probing microRNAs with microarrays: Tissue specificity and functional inference
}

\author{
TOMAS BABAK, ${ }^{1,2}$ WEN ZHANG, ${ }^{1,2}$ QUAID MORRIS, ${ }^{1}$ BENJAMIN J. BLENCOWE, ${ }^{1,2}$ \\ and TIMOTHY R. HUGHES ${ }^{1,2}$ \\ ${ }^{1}$ Banting and Best Department of Medical Research, University of Toronto, Toronto, Ontario M5G 1L6, Canada \\ ${ }^{2}$ Department of Medical Genetics and Microbiology, University of Toronto, Toronto, Ontario M1R 4F9, Canada
}

\begin{abstract}
MicroRNAs (miRNAs) are short, stable, noncoding RNAs involved in post-transcriptional gene silencing via hybridization to mRNA. Few have been thoroughly characterized in any species. Here, we describe a method to detect miRNAs using microarrays, in which the miRNAs are directly hybridized to the array. We used this method to analyze miRNA expression across 17 mouse organs and tissues. More than half of the 78 miRNAs detected were expressed in specific adult tissues, suggesting that miRNAs have widespread regulatory roles in adults. By comparing miRNA levels to mRNA levels determined in a parallel microarray analysis of the same tissues, we found that the expression of target mRNAs predicted on the basis of sequence complementarity is unrelated to the tissues in which the corresponding miRNA is expressed.
\end{abstract}

Keywords: microRNAs; microarrays; transcription; gene regulation; RNA processing; mouse

\section{INTRODUCTION}

Since the discovery of the first miRNAs lin-4 and let-7, computational and molecular cloning approaches have revealed hundreds of miRNAs in a variety of organisms (Lee et al. 1993; Lau et al. 2001; Lagos-Quintana et al. 2002, 2003; Ambros et al. 2003; Houbaviy et al. 2003; Lee and Ambros 2001; Lim et al. 2003; Kim et al. 2004) including $>200$ different mammalian miRNAs (Ambros et al. 2003). MicroRNAs are transcribed as mono- or polycistronic precursors that are processed by the nuclear RNAse III enzyme Drosha to $\sim 70$-nt hairpins with 3 '-overhangs (pre-miRNAs) (Lee et al. 2003). The export of pre-miRNAs into the cytoplasm, a step that is believed to be regulated, is mediated by exportin-5 (Yi et al. 2003; Bohnsack et al. 2004; Lund et al. 2004). Pre-miRNAs are further processed by Dicer, another RNase III-related enzyme, to yield the mature 17-24-nt products. Although screens for novel miRNAs appear to be approaching saturation (Lim et al. 2003), and the mechanism of miRNA-mediated silencing is gradually being uncovered (Tijsterman and Plasterk 2004), few advances have

Reprint requests to: Timothy R. Hughes, Banting and Best Department of Medical Research, 112 College St., University of Toronto, Toronto, Ontario M5G 1L6, Canada; e-mail: t.hughes@utoronto.ca; fax: (416) 9788528.

Article and publication are at http://www.rnajournal.org/cgi/doi/ 10.1261/rna.7119904. been made in determining the functional roles of specific miRNAs. Only one mammalian target, for example, has been verified in vivo, and represents a rare case in which the miRNA sequence matches the target mRNA with near perfect complementarity (Yekta et al. 2004).

Relative expression levels of microRNAs in different tissues can provide clues about their physiological functions. However, knowledge regarding miRNA expression patterns is currently restricted to a subset of known miRNAs and includes only a handful of major organs and cell lines (Lau et al. 2001; Lagos-Quintana et al. 2002; Houbaviy et al. 2003; Lim et al. 2003; Sempere et al. 2004). This is due in part to limitations of current miRNA detection assays. Northern blotting becomes labor-intensive as a highthroughput approach, and RT-PCR is restricted to the detection of miRNA precursors (Schmittgen et al. 2004). A modified mRNA "invader" assay was applied to miRNAs revealing highly sensitive and specific miRNA detection (Allawi et al. 2004), but its high-throughput feasibility has not been demonstrated. Nylon membrane arrays (i.e., dotblots) have been used to detect miRNAs in brain, but this technique requires radioisotope labeling (Krichevsky et al. 2003). Recently, a microarray detection approach was described in which miRNAs were reverse-transcribed with biotinylated random primers and hybridized to oligonucleotide spotted arrays (Liu et al. 2004). MicroRNA levels were then detected using streptavidin-bound fluorophores. 
Here, we describe a novel method in which fluor-labeled miRNAs are directly detected using inkjet-printed microarrays. The method can distinguish between precursor miRNAs and their fully processed products, and has sensitivity and specificity comparable to Northern blotting, on the basis of comparisons to our own experiments and to data in the literature. We have applied the method to a panel of 17 mouse tissues and organs in which we have also analyzed levels of mRNAs. Examination of whether miRNAs are coexpressed with target mRNAs, predicted on the basis of sequence complementarity, indicates that miRNAs are no more frequently expressed in the tissues that express the predicted target mRNAs than would be expected by chance.

\section{RESULTS AND DISCUSSION}

Peng et al. (2003) recently described a method for analysis of noncoding RNAs in yeast using DNA microarrays in which the RNAs are covalently labeled with fluors (Wiegant et al. 1999) and hybridized directly to an array of oligonucleotides complementary to the RNA sequences. To ask whether this approach is applicable to the detection of miRNAs, we fluor-labeled total RNA from 17 different mouse tissue samples and hybridized the labeled RNA to custom inkjet-printed microarrays (Hughes et al. 2001) containing oligonucleotide sequences complementary to 154 miRNAs and 206 other mouse noncoding RNAs that
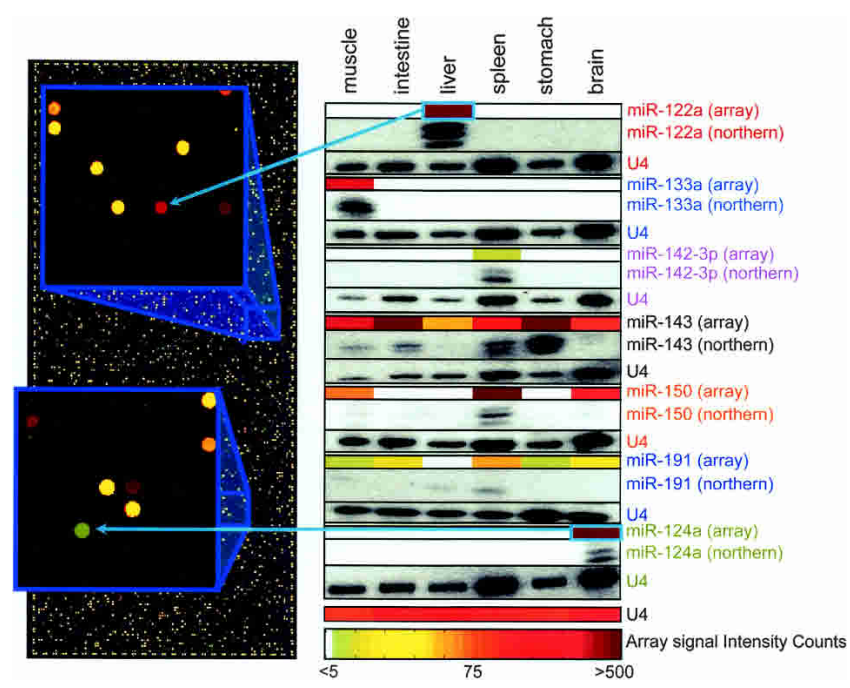

FIGURE 1. Detection of miRNAs by microarrays. Total RNA extracted from brain and liver was covalently labeled with Cy3 (green channel) and Cy5 (red channel), respectively, and hybridized to the array. The same RNAs, in addition to five others, were analyzed by Northern blotting (shown at right). The scanner counts are background-subtracted; median values for tRNA and rRNA positive control spots on the same arrays were $\sim 100$ and $\sim 25,000$, respectively. A sample image of an entire Northern blot is available in Supplemental Figure S1 (see Supplemental Material at http://hugheslab.med. utoronto.ca/Babak).

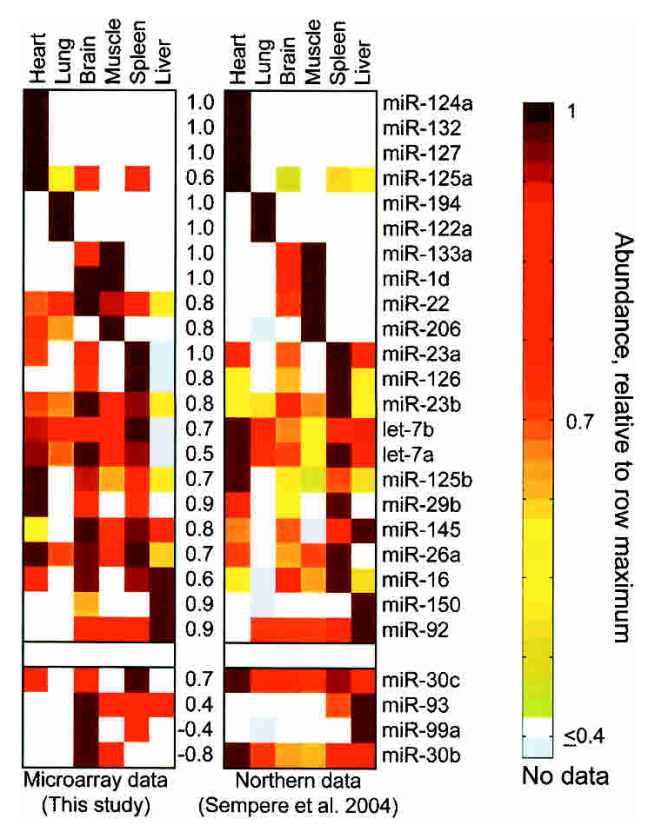

FIGURE 2. MicroRNA microarray data from directly labeled miRNA agree with previously published Northern analyses (Sempere et al. 2004). Shown are all miRNAs detected using microarrays in this study (left) at a signal threshold $>99 \%$ that of negative control probes in at least one tissue, and by Northern analysis in a previous study (Sempere et al. 2004) with a cutoff signal/background ratio of 1.3 (right) (L. Sempere and V. Ambros, pers. comm.). Within each study, the rows were normalized to a maximum value of 1 to allow direct comparison of the data sets. More than $95 \%$ of the normalized values between 0 and 0.4 were zero. The numbers between the two panels are the $r$-values of the Pearson correlation for each miRNA between the two studies.

were included as controls. Figure 1 shows an image of a microarray hybridized with total mouse liver (Cy3) and brain (Cy5) RNAs. Hybridization signals for seven miRNAs with tissue-specific expression confirmed by Northern analysis are shown.

We compared our total miRNA detection results with recently published expression data generated by Northern analysis of the same tissues (Sempere et al. 2004) and obtained a clear correlation (Fig. 2; average Pearson correlation of 0.70 for the 26 miRNAs shown, vs. a correlation of 0.02 if the row and column order of the same data are randomized). This overlap represents the intersection of tissues and miRNAs for which both we and the Sempere group obtained significant signals (43/154 by microarray, and $58 / 120$ by Northern in these tissues) (Sempere et al. 2004). In four cases, our data disagreed with the Sempere study in some or all of the tissues (Fig. 2, bottom). Our Northern analyses of these cases indicated that low miRNA transcript abundance is likely the source of the discrepancies (Supplemental Fig. S2 at http://hugheslab.med.utoronto. ca/Babak). Discrepancies could also stem from differences between the individual samples analyzed, differences in methodology, or differences in the analysis of the Northern blots. 
To assess to what extent signals from the miRNA spots corresponded to the mature $\sim 21-n t$ miRNAs or larger precursor RNAs, we measured hybridization intensities of probes tiled every 7 bases across miRNA precursors, in addition to $100 \mathrm{nt}$ of flanking sequence extracted from corresponding genomic sequence. Tiling across miR-201, miR$30 \mathrm{a}$, and miR-183 revealed subthreshold intensities across the entire precursor sequences except where the probe positions corresponded exactly to the mature miRNA (Fig. 3). The vast majority of examples analyzed follow this trend (see Supplemental Fig. S2 at http://hugheslab.med.utoronto. $\mathrm{ca} /$ Babak). Moreover, in the seven Northern blots shown in Figure 1, no precursor bands were visible (Supplemental Fig. S1; data not shown), supporting the results from the microarray data. This indicates that in the 17 tissues analyzed, there is unlikely to be a substantial miRNA precursor

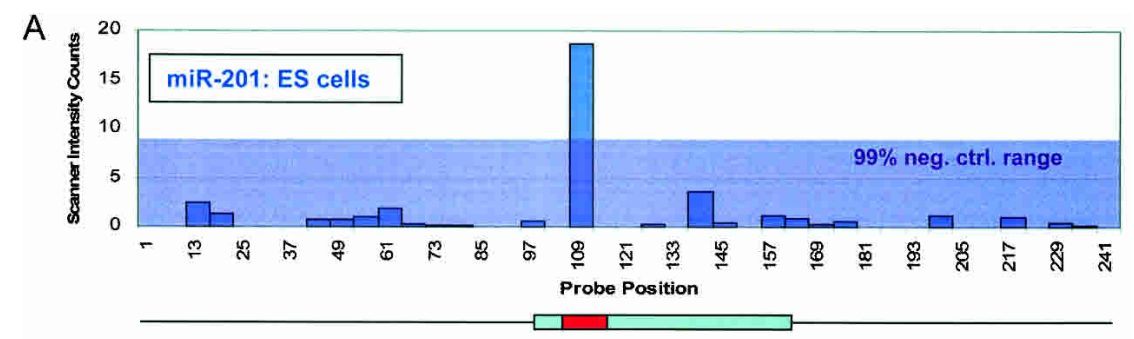

B

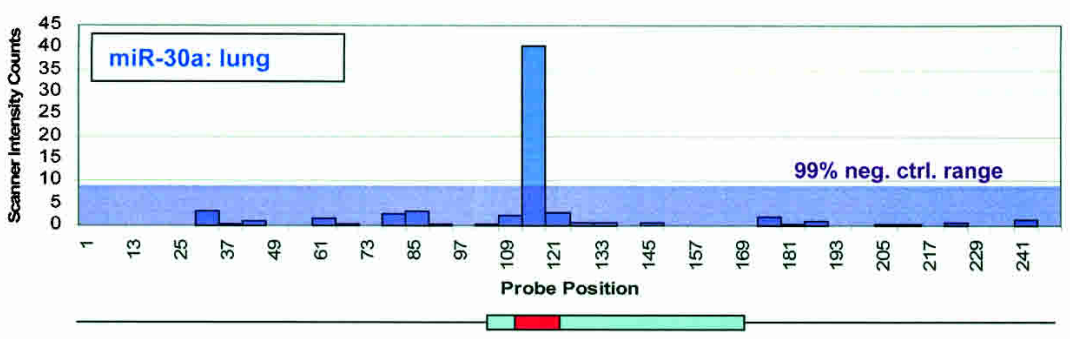

C
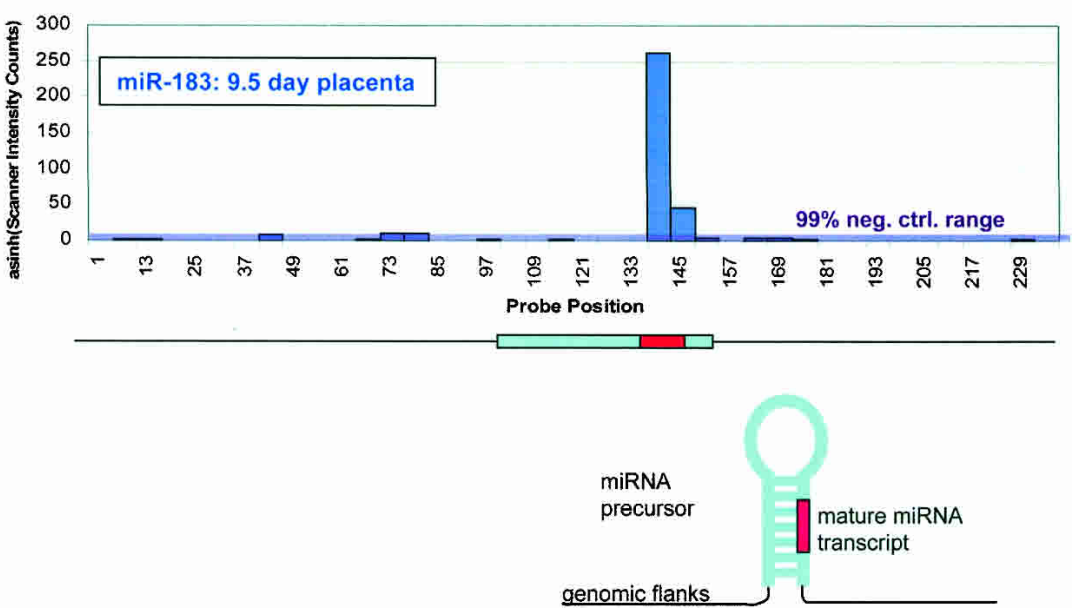

FIGURE 3. MicroRNA microarray probes distinguish mature miRNAs from flanking sequence. Probes were tiled every $7 \mathrm{nt}$ across miRNA-precursors including 100-nt $5^{\prime}$ - and $3^{\prime}$-flanking genomic sequence on both ends. $(A)$ miR-201 profile from RNA extracted from ES cells; $(B)$ miR-30a profile from RNA extracted from lung; $(C)$ miR-183 profile from RNA extracted from 9.5-d placenta. Shaded regions indicate the intensity range of $99 \%$ negative control measurements (200 random sequences per array, compounded over 17 experiments). pool. Figure 4 shows a "clustergram" of the 78 miRNAs ( $51 \%$ of the 154 miRNAs represented on the array) that we detected in at least one tissue at an intensity $>99 \%$ of our negative control probes (200 random-sequence oligonucleotides on the array) (see Materials and Methods). Most miRNAs we detected were tissue-specific, and most were expressed in adult organs to a greater extent than in embryonic tissues. The brain displayed the highest proportion of tissue-specific miRNAs, consistent with published miRNA data (Kim et al. 2004; Sempere et al. 2004) and also with accumulating evidence of widespread post-transcripthe brain (Jiang and Schuman 2002; Perrone-Bizzozero and Bolognani 2002). The three embryonic stages represented in this analysis $(9.5,12.5$, and 15 d post-coitum, dpc) also expressed specific miRNAs, despite the whole embryos being a mixture of many developing organs and cell types. For example, miR-91-13b and miR-92 are most highly expressed at $9.5 \mathrm{dpc}$, whereas miR-213, miR-214, miR-297, and miR298 are highly represented at the later stages. The let-7 family also appears between stages 12.5 and $15 \mathrm{dpc}$ and persists in all adult tissues, analogous to its expression in Caenorhabditis elegans, where it is first expressed at L3 and persists through adulthood (Reinhart et al. 2000; Lau et al. 2001). Another set of highly tissue-specific miRNAs is found in embryonic stem (ES) cells, consisting of the previously reported miR-15b, miR-106a, and the miR-290 set (Houbaviy et al. 2003), in addition to miR201 and miR-105.

We reasoned that data on the tissuespecific expression of miRNAs might facilitate inference of their functional roles and the prediction of their potential mRNA targets using sequence-based methods (Enright et al. 2003; Lewis et al. 2003). We first asked whether there is a correspondence between the expression of miRNAs and the expression of their targets predicted on the basis of sequence complementarity. To this end, we used an mRNA expression data set (W. Zhang, Q. Morris, R. Chang, O. Shai, M.A. Bakowski, N. Mitsakakis, N. Mohammad, M. Robinson, R. Zirnglibl, E. Somogyi et al., in prep.) that assayed the same 17 mouse tissues in which we surveyed miRNA expression. We used the miRNA target prediction algorithms TargetScan (Lewis et al. 2003) and Miranda (Enright et al. 2003) on the Ref- 


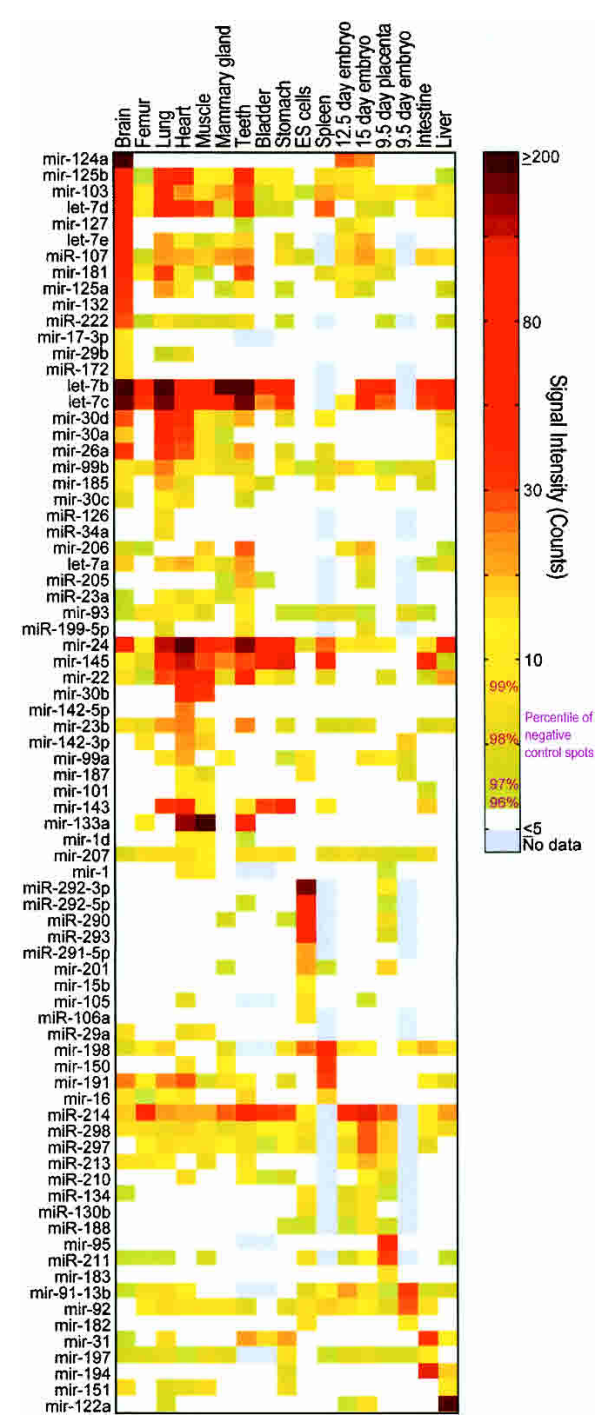

FIGURE 4. Expression profiles of 78 miRNAs across 17 mouse tissues reveal tissue-specific expression of the majority of miRNAs detected. Expression data were subset to miRNAs with a signal threshold $>99 \%$ of the negative control probes in at least one tissue. The intensity scale represents background-subtracted normalized scanner intensity counts, with the negative control probe thresholds indicated.

Seq mRNAs that were expressed in at least one of the tissues assayed for miRNA expression (10,209 genes), to identify potential targets on the basis of sequence.

We did not observe a strong correlation between the expression profiles of miRNAs and the expression profiles of their predicted mRNA targets (data not shown). Moreover, we found that mRNA targets predicted by either program were no more frequently expressed in the same tissues as their predicted regulatory miRNAs, than were randomly selected targets (Fig. 5A) (random selection was restricted to mRNAs that were detected in an identical number of tissues as the predicted targets, to control for inherent higher overlap with targets that are expressed in more tissues). This trend was not as obvious when the predicted targets were subset to conserved $3^{\prime}$-UTRs. (Figure 5 shows the Miranda-predicted targets, when restricting the analysis to conserved 3 '-UTR sequences.) The higher expression overlap with $3^{\prime}$-UTRs arises because of a tendency for genes with conserved $3^{\prime}$-UTRs to be expressed in more tissues (targets expressed in all tissues, e.g., will always overlap perfectly with miRNA expression, i.e., Jaccard's similarity coeff. $=1$ ) (see Supplemental Fig. S4 at http://hugheslab. med.utoronto.ca/Babak), and the greater variance in overlap is presumably caused by the smaller sample size. Figure 5B shows a similar analysis with randomly selected mRNA targets on both axes, to illustrate the variation in overlap that is associated with random resampling. We conclude that there is little or no relationship between the expression of miRNAs and expression of their predicted mRNA targets, and that restricting miRNA target predictions to conserved 3'-UTRs does not appear to improve the correspondence. Because some such relationships could occur by chance (Fig. 5B), we take them to be likely random noise. Interpretation and applications of this observation are discussed below.

\section{CONCLUSIONS}

Our results show that miRNAs are amenable to direct detection using microarrays. The results we obtained with microarrays are consistent with our results from Northern blotting, and are also generally consistent with miRNA expression data reported in the literature. This indicates that our microarray system is comparable to other measurement approaches in terms of specificity and sensitivity. During the preparation of this manuscript, a spotted oligonucleotide microarray approach was reported (Liu et al. 2004), in which arrays were hybridized with biotinylated reversetranscribed miRNAs and detected with streptavidin-bound fluorophores. Although this study did not provide numerical quantification with which we could directly compare the data, several features agreed well with our measurements. In both studies, it was found that different tissues have distinct miRNA expression profiles and that related tissues/organs (e.g., heart and muscle) have more similar profiles than more functionally distant tissues/organs. Moreover, all human tissue-specific miRNAs reported in the figures by Liu et al. (2004) agree well with our data. For example, seven of eight miRNAs that were reported to be brain-specific by Liu et al. (2004) were also brain-specific in our analysis. The single difference was miR-95, which may be a human-specific brain transcript. One parameter that is not measured by microarrays is the length of the species detected; however, because the flexible array technology we are using allows many more spots than there are miRNAs, a tiling strategy can be used to determine whether the signal is derived from precursor or final product miRNAs. Our microarray data and follow-up analysis indicate that virtually all of the miRNAs we detected are fully processed. 

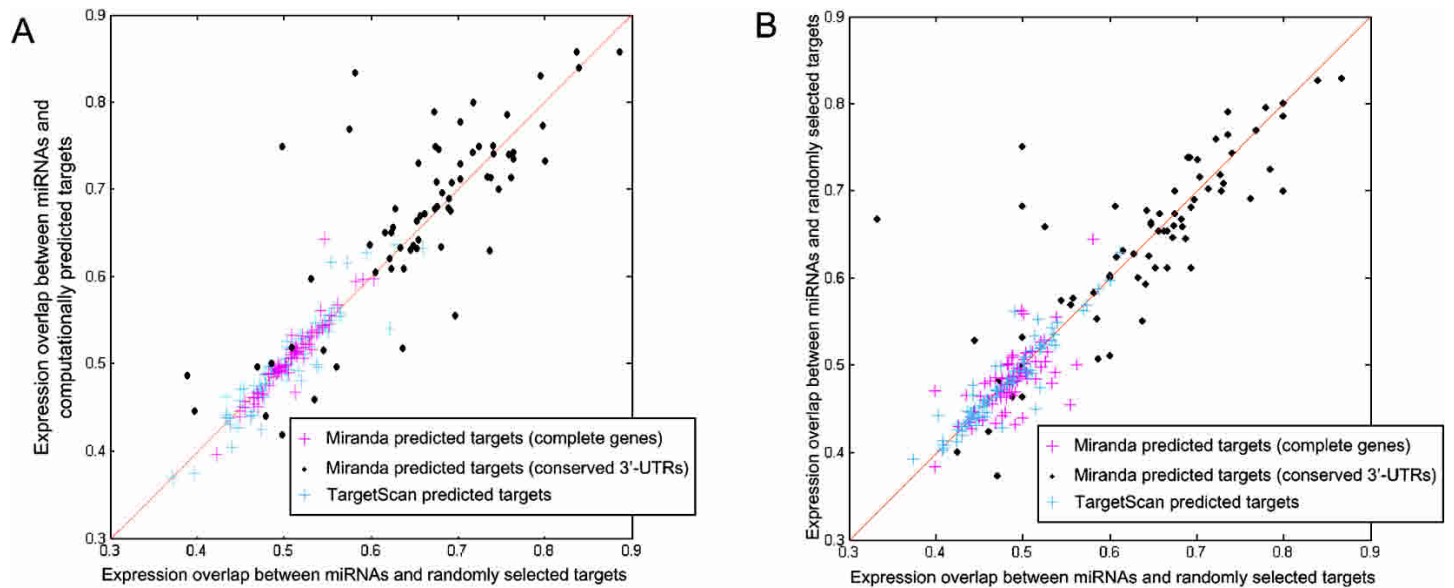

FIGURE 5. mRNAs are not biased toward being expressed in the same tissues as miRNAs that are predicted to target them. The expression overlap between each sequence-predicted miRNA-mRNA target pair was calculated using Jaccard's similarity coefficient and then averaged over all targets for that miRNA. This was repeated for the same number of randomly selected targets with an equal expression distribution (each target was replaced by a randomly selected target expressed in the same number of tissues). (A) The predicted target overlap scores are plotted versus overlap scores of randomly selected target scores. Of the Miranda-predicted targets, $55 \%$ had a better overlap with predicted targets than randomly selected targets (these fell above the line; using full-sequence RefSeq genes, default settings, shuffling enabled, $z_{\text {Miranda }}>5$ ). Similarly, 56\% of TargetScan-predicted targets had a better overlap with predicted targets than randomly selected targets (full-sequence RefSeq genes, default settings, $z_{\text {Targetscan }}>4$; higher $z$ thresholds did not improve the overlap). Restricting targets to conserved $3^{\prime}$-UTRs did not visibly improve the overlap (Miranda results shown). (B) The same analysis was performed using two sets of randomly selected targets to demonstrate the degree of variability that arises from random resampling.

Our results indicate that most miRNAs expressed in adults are tissue-specific. The tissue range in which a miRNA is expressed places an obvious constraint on its physiological role(s), as well as on its possible mRNA target(s). Our analysis indicates that mRNA targets predicted on the basis of sequence display no higher coexpression with the corresponding miRNA than do randomly selected mRNAs. This supports the currently favored model that most mammalian miRNAs act by inhibiting translation without target degradation (Bartel 2004; Yekta et al. 2004); if the mechanism were via tissue-specific degradation, then a negative correlation would be observed (i.e., the points would be below the line in Fig. 5A). Rather, the correlation between miRNA expression and mRNA expression we observed is not significant (if it were, then many of the data points in Fig. 5A would be away from the diagonal).

We suggest that a combination of sequence and expression analysis might yield improved prediction of the mRNA targets of miRNAs. Given that there is only one in vivoverified miRNA target in mammals, and no homologs of verified targets in other species, we cannot determine whether sequence-based or expression-based predictions of miRNA functions are more accurate, nor can we assess whether the overlap is enriched for bona fide functions and targets without extensive de novo experimentation. To facilitate such experimentation, we have subset the Mirandaand TargetScan-predicted targets for each of the 78 miRNAs we detected to those that are expressed in at least one of the tissues in which the miRNA is expressed. In addition, if the true miRNA targets are expected to be present in the same tissues as the miRNAs themselves, then one can apply sta- tistical inference methods to predict the functions of miRNAs on the basis of similarities between expression profiles of miRNA and expression profiles of mRNAs with known functions; the latter taken as a proxy for the profiles of functional categories. To this end, we ran Support Vector Machines (SVM) (Brown et al. 2000) over 992 Gene Ontology (Ashburner et al. 2000) "Biological Process" categories for all miRNAs detected on the microarray, by comparing their expression to the expression of the 21,575 mRNAs assayed in the same tissues. We list SVMpredicted functions for each of them in the Supplemental Material (http://hugheslab.med.utoronto.ca/Babak), together with a confidence estimate that the prediction is correct. These will provide a guide for directed experimentation toward understanding the physiological role of the miRNAs.

\section{MATERIALS AND METHODS}

\section{miRNA microarray design}

Nonredundant mature human and mouse miRNA sequences were downloaded from the miRNA registry (Ambros et al. 2003). The 154 miRNA probe sequences were designed to be complementary to the full-length mature miRNA; melting temperatures of $90 \%$ were between $51^{\circ} \mathrm{C}$ and $59^{\circ} \mathrm{C}$ (avg. $T_{\mathrm{m}}=54.0^{\circ} \mathrm{C}, \mathrm{SD} 3.64$ ). In addition, complementary probes for 206 additional mouse ncRNAs (e.g., rRNA, tRNA, snoRNAs, XIST) were generated by tiling $T_{\mathrm{m}}$-balanced probes $\left(55^{\circ} \mathrm{C}\right)$ across the transcripts and were included as controls for normalization purposes. Probes for miRNA precursors and flanking genomic sequences were designed 
similarly. DNA probe sequences were on average $24 \mathrm{nt}$ and were concatenated up to $60 \mathrm{nt}$. Probe sequences were submitted to Agilent Technologies for microarray production. The designs included 20060 -nt oligonucleotide probes containing random sequences, which were used as negative controls. The Supplemental Material (see http://hugheslab.med.utoronto.ca/Babak) contains a file of all of the probe sequences.

\section{RNA extraction, labeling, and hybridizations}

Total RNA was extracted using Trizol (Invitrogen) according to the manufacturer's instructions and treated with DNAse I (Fermentas). The integrity of the rRNA was confirmed on $1 \%$ agaroseformaldehyde gels, and $7 \mu \mathrm{g}$ of total RNA was chemically labeled with Ulysis Alexa Fluor 546 or Ulysis Alexa Fluor 647 (Molecular Probes) according to the manufacturer's instructions. This protocol labels $G$ residues (Wiegant et al. 1999), and there are no mouse miRNAs that lack a $\mathrm{G}$ residue. Samples were resuspended in 0.5 $\mathrm{mL}$ of hybridization buffer $(1 \mathrm{M} \mathrm{NaCl}, 0.5 \%$ sodium sarcosine, 50 $\mathrm{mM}$ methyl ethane sulfonate at $\mathrm{pH} 6.5,33 \%$ formamide, and 40 $\mu \mathrm{g}$ salmon sperm DNA), denatured by heating for $5 \mathrm{~min}$ at $65^{\circ} \mathrm{C}$, and snap-cooled on ice prior to hybridization. Hybridizations were carried out in duplicate (two samples per array labeled with different fluorophores) for $16-24 \mathrm{~h}$ at $42^{\circ} \mathrm{C}$ in a rotating hyb oven. Slides were then washed (rocking for $\sim 30 \mathrm{sec}$ in $6 \times$ SSPE, $0.005 \%$ sarcosine, then rocking for $\sim 30 \mathrm{sec}$ in $0.06 \times$ SSPE) and scanned with a $4000 \mathrm{~A}$ microarray scanner (Axon Instruments).

\section{Microarray data processing and normalization}

TIFF images were quantified with GenePix 3.0 (Axon Instruments). Individual channels were spatially detrended (i.e., overall correlations between spot intensity and position on the slide removed) by high-pass filtering (Shai et al. 2003) using 5\% outliers. The 17 individual channels were then normalized using Variance Stabilizing Normalization (Huber et al. 2002) and transformed to arcsinh values, which are similar to natural log values but are tolerant of negative numbers emerging from high-pass filtering. Repeat measurements from separate arrays revealed an average Pearson correlation of 0.82 across 13 repeated tissues for all miRNAs, and 0.94 when restricted to intensities above the $99 \%$ negative-control threshold.

\section{Northern blotting}

For Northern blotting, $7 \mu \mathrm{g}$ of total RNA from each tissue was separated on $15 \%$ or $20 \%$ polyacrylamide/TBE/urea gels, and electroblotted to Hybond $\mathrm{N}^{+}$membranes (Amersham) using a wettransfer apparatus (BioRad) in $50 \mathrm{mM} \mathrm{Na}_{2} \mathrm{H}_{2} \mathrm{PO}_{4}, 100 \mathrm{mM}$ citric acid buffer. The membranes were UV cross-linked using a Stratalinker (Stratagene), hybridized overnight at $28^{\circ} \mathrm{C}$ in Church buffer with $5^{\prime}-{ }^{32} \mathrm{P}$-end-labeled oligonucleotide probes, and washed as described (Peng et al. 2003). Results were analyzed using a PhosphorImager (BioRad Personal FX). The oligonucleotide probe sequences in Figure 1 are ACAAACACCATTGTCACACT CCA (miR-122a), CAGCTGGTTGAAGGGGACCAA (miR-133), CCATAAAGTAGGAAACACTACA (miR-142-3p), TGAGCTACA GTGCTTCATCTCA (miR-143), CACTGGTACAAGGGTTGGGA
GA (miR-150), AGCTGCTTTTGGGATTCCGTTG (miR-191), TGGCATTCACCGCGTGCCTTAA (miR-124a), and CCTCGGA TAAACCTCATTGGCTA (U4).

\section{miRNA/mRNA target expression overlap analysis}

The full RefSeq collection of mouse and human mRNAs was downloaded from NCBI (ftp://ftp.ncbi.nih.gov/refseq). Miranda (Enright et al. 2003) and TargetScan (Lewis et al. 2003) were run on the full sequences using default settings with shuffling enabled in the case of Miranda. The genes were then subset to transcripts that were represented in our parallel microarray analysis (W. Zhang, Q. Morris, R. Chang, O. Shai, M.A. Bakowski, N. Mitsakakis, N. Mohammad, M. Robinson, R. Zirnglibl, E. Somogyi et al., in prep.) and that were expressed in at least one of the 17 tissues analyzed in this study (10,209 genes). 3'-UTRs were identified by extracting CDS positions from GenBank flatfiles and then parsing the FASTA files. The human and mouse versions were aligned to identify conserved elements using BLAST (word size 7, otherwise default settings). The expression data were then transformed to binary form using a signal intensity threshold of $99 \%$ of negative control microarray spots. Jaccard's Similarity coefficient (Rasmussen 1992) was then calculated for each miRNA-target prediction and averaged over all predicted targets to reveal an "expression overlap" score for each miRNA (essentially measuring the rate at which predicted mRNA targets are expressed in the same tissues as their corresponding miRNA). These scores were compared with scores generated using randomly selected mRNAs with an identical distribution of the number of tissues in which the mRNAs are expressed (e.g., a predicted target mRNA expressed in five tissues was replaced with a randomly selected mRNA expressed in five tissues). This comparison was drawn using various subsets of targets distinguished on the basis of confidence thresholds ( $z_{\text {TargetScan }}$, e.g., corresponds mostly to the number of predicted target sites in the sequence) and the position of the predicted target sites (if they are located in conserved $3^{\prime}$-UTRs, e.g.).

\section{Data availability}

Oligonucleotide sequences and miRNA data are posted at http:// hugheslab.med.utoronto.ca/Babak and have been submitted to NCBI GEO. mRNA microarray data will be described elsewhere (W. Zhang, Q. Morris, R. Chang, O. Shai, M.A. Bakowski, N. Mitsakakis, N. Mohammad, M. Robinson, R. Zirnglibl, E. Somogyi et al., in prep.) and are posted together with Gene Ontology annotations at http://hugheslab.med.utoronto.ca/Zhang.

\section{ACKNOWLEDGMENTS}

We thank Lorenzo Sempere and Victor Ambros for sharing primary data from Northern analysis, and Ofer Shai and Brendan Frey for help and advice with image processing. This work was supported by grants to T.R.H. and B.J.B. from CIHR and CFI. T.B. was supported by an NSERC graduate scholarship.

Received July 6, 2004; accepted August 11, 2004.

\section{REFERENCES}

Allawi, H.T., Dahlberg, J.E., Olson, S., Lund, E., Olson, M., Ma, W.P., Takova, T., Neri, B.P., and Lyamichev, V.I. 2004. Quantitation of microRNAs using a modified Invader assay. RNA 10: 1153-1161. 
Ambros, V., Bartel, B., Bartel, D.P., Burge, C.B., Carrington, J.C., Chen, X., Dreyfuss, G., Eddy, S.R., Griffiths-Jones, S., Marshall, M., et al. 2003. A uniform system for microRNA annotation. RNA 9: 277-279.

Ashburner, M., Ball, C.A., Blake, J.A., Botstein, D., Butler, H., Cherry, J.M., Davis, A.P., Dolinski, K., Dwight, S.S., Eppig, J.T., et al. 2000. The Gene Ontology Consortium. Gene ontology: Tool for the unification of biology. Nat. Genet. 25: 25-29.

Bartel, D.P. 2004. MicroRNAs: Genomics, biogenesis, mechanism, and function. Cell 116: 281-297.

Bohnsack, M.T., Czaplinski, K., and Gorlich, D. 2004. Exportin 5 is a RanGTP-dependent dsRNA-binding protein that mediates nuclear export of pre-miRNAs. RNA 10: 185-191.

Brown, M.P., Grundy, W.N., Lin, D., Cristianini, N., Sugnet, C.W., Furey, T.S., Ares Jr., M., and Haussler, D. 2000. Knowledge-based analysis of microarray gene expression data by using support vector machines. Proc Natl Acad. Sci. 97: 262-267.

Enright, A.J., John, B., Gaul, U., Tuschl, T., Sander, C., and Marks, D.S. 2003. MicroRNA targets in Drosophila. Genome Biol. 5: R1.

Houbaviy, H.B., Murray, M.F., and Sharp, P.A. 2003. Embryonic stem cell-specific microRNAs. Dev. Cell 5: 351-358.

Huber, W., Von Heydebreck, A., Sultmann, H., Poustka, A., and Vingron, M. 2002. Variance stabilization applied to microarray data calibration and to the quantification of differential expression. Bioinformatics 18: Suppl. 1, S96-S104.

Hughes, T.R., Mao, M., Jones, A.R., Burchard, J., Marton, M.J., Shannon, K.W., Lefkowitz, S.M., Ziman, M., Schelter, J.M., Meyer, M.R., et al. 2001. Expression profiling using microarrays fabricated by an ink-jet oligonucleotide synthesizer. Nat. Biotechnol. 19: 342347.

Jiang, C. and Schuman, E.M. 2002. Regulation and function of local protein synthesis in neuronal dendrites. Trends Biochem. Sci. 10: $506-513$.

Kim, J., Krichevsky, A., Grad, Y., Hayes, G.D., Kosik, K.S., Church, G.M., and Ruvkun, G. 2004. Identification of many microRNAs that copurify with polyribosomes in mammalian neurons. Proc. Natl. Acad. Sci. 101: 360-365.

Krichevsky, A.M., King, K.S., Donahue, C.P., Khrapko, K., and Kosik, K.S. 2003. A microRNA array reveals extensive regulation of microRNAs during brain development. RNA 9: 1274-1281.

Lagos-Quintana, M., Rauhut, R., Yalcin, A., Meyer, J., Lendeckel, W., and Tuschl, T. 2002. Identification of tissue-specific microRNAs from mouse. Curr. Biol. 12: 735-739.

Lagos-Quintana, M., Rauhut, R., Meyer, J., Borkhardt, A., and Tuschl, T. 2003. New microRNAs from mouse and human. RNA 9: 175179.

Lau, N.C., Lim, L.P., Weinstein, E.G., and Bartel, D.P. 2001. An abundant class of tiny RNAs with probable regulatory roles in Caenorhabditis elegans. Science 294: 858-862.

Lee, R.C. and Ambros, V. 2001. An extensive class of small RNAs in Caenorhabditis elegans. Science 294: 862-864.

Lee, R.C., Feinbaum, R.L., and Ambros, V. 1993. The C. elegans heterochronic gene lin-4 encodes small RNAs with antisense comple- mentarity to lin-14. Cell 75: 843-854.

Lee, Y., Ahn, C., Han, J., Choi, H., Kim, J., Yim, J., Lee, J., Provost, P., Radmark, O., Kim, S., et al. 2003. The nuclear RNase III Drosha initiates microRNA processing. Nature 425: 415-419.

Lewis, B.P., Shih, I.H., Jones-Rhoades, M.W., Bartel, D.P., and Burge, C.B. 2003. Prediction of mammalian microRNA targets. Cell 115: 787-798.

Lim, L.P., Glasner, M.E., Yekta, S., Burge, C.B., and Bartel, D.P. 2003. Vertebrate microRNA genes. Science 299: 1540.

Liu, C.G., Calin, G.A., Meloon, B., Gamliel, N., Sevignani, C., Ferracin, M., Dumitru, C.D., Shimizu, M., Zupo, S., Dono, M., et al. 2004. An oligonucleotide microchip for genome-wide microRNA profiling in human and mouse tissues. Proc. Natl. Acad. Sci. 101: 97409744.

Lund, E., Guttinger, S., Calado, A., Dahlberg, J.E., and Kutay, U. 2004. Nuclear export of microRNA precursors. Science 303: 95-98.

Peng, W.T., Robinson, M.D., Mnaimneh, S., Krogan, N.J., Cagney, G., Morris, Q., Davierwala, A.P., Grigull, J., Yang, X., Zhang, W., et al. 2003. A panoramic view of yeast noncoding RNA processing. Cell 113: 919-933.

Perrone-Bizzozero, N. and Bolognani, F. 2002. Role of HuD and other RNA-binding proteins in neural development and plasticity. $J$. Neurosci. Res. 68: 121-126.

Rasmussen, E. 1992. In Information retrieval: Data structures and algorithms (eds. W.B. Frakes and R. Baeza-Yates), pp. 419-442. Prentice Hall, Englewood Cliffs, NJ.

Reinhart, B.J., Slack, F.J., Basson, M., Pasquinelli, A.E., Bettinger, J.C., Rougvie, A.E., Horvitz, H.R., and Ruvkun, G. 2000. The 21nucleotide let-7 RNA regulates developmental timing in Caenorhabditis elegans. Nature 403: 901-906.

Schmittgen, T.D., Jiang, J., Liu, Q., and Yang, L. 2004. A highthroughput method to monitor the expression of microRNA precursors. Nucleic Acids Res. 32: e43.

Sempere, L.F., Freemantle, S., Pitha-Rowe, I., Moss, E., Dmitrovsky, E., and Ambros, V. 2004. Expression profiling of mammalian microRNAs uncovers a subset of brain-expressed microRNAs with possible roles in murine and human neuronal differentiation. Genome Biol. 5: R13.

Shai, O., Morris, Q., and Frey, B.J. 2003. Spatial bias removal in microarray images, University of Toronto Technical Report PSI-200321. http://hugheslab.med.utoronto.ca/Zhang/techReport.pdf.

Tijsterman, M. and Plasterk, R.H. 2004. Dicers at RISC; the mechanism of RNAi. Cell 117: 1-3.

Wiegant, J.C., van Gijlswijk, R.P., Heetebrij, R.J., Bezrookove, V., Raap, A.K., and Tanke, H.J. 1999. ULS: A versatile method of labeling nucleic acids for FISH based on a monofunctional reaction of cisplatin derivatives with guanine moieties. Cytogenet. Cell Genet. 87: 47-52.

Yekta, S., Shih, I.H., and Bartel, D.P. 2004. MicroRNA-directed cleavage of HOXB8 mRNA. Science 304: 594-596.

Yi, R., Qin, Y., Macara, I.G., and Cullen, B.R. 2003. Exportin-5 mediates the nuclear export of pre-microRNAs and short hairpin RNAs. Genes \& Dev. 15: 3011-3016. 
RNA 10: 1813-1819 (2004)

\section{Probing microRNAs with microarrays: Tissue specificity and functional inference}

TOMAS BABAK, WEN ZHANG, QUAID MORRIS, BENJAMIN J. BLENCOWE, and TIMOTHY R. HUGHES

The first two panels in Figure 2 in this paper were incorrectly labeled. They should read (from left): Brain, Liver, Heart, Muscle, Lung, Spleen. The authors apologize for any confusion this may have caused.

RNA 10: 1900-1906 (2004)

\section{Generation of a catalytic module on a self-folding RNA}

WATARU YOSHIOKA, YOSHIYA IKAWA, LUC JAEGER, HIDEAKI SHIRAISHI, and TAN INOUE

Co-author Luc Jaeger's correct affiliation is Department of Chemistry and Biochemistry, University of California at Santa Barbara, CA 93106, USA. Inadvertently, University of California at San Bernadino was noted instead. 

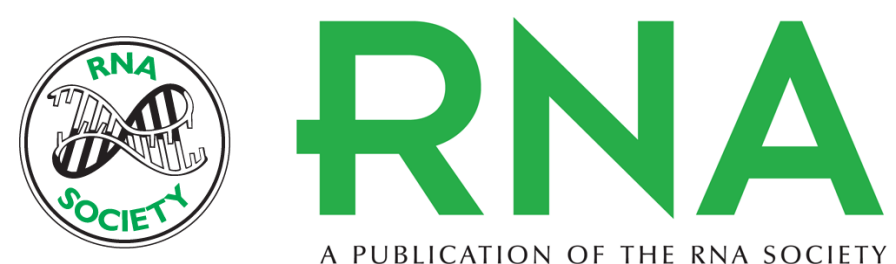

A PUBLICATION OF THE RNA SOCIETY

\section{Probing microRNAs with microarrays: Tissue specificity and functional inference}

TOMAS BABAK, WEN ZHANG, QUAID MORRIS, et al.

RNA 2004 10: 1813-1819

\footnotetext{
Related Content

Probing microRNAs with microarrays: Tissue specificity and functional inference TOMAS BABAK, WEN ZHANG, QUAID MORRIS, et al.

RNA January , 2005 11: 114

References This article cites 30 articles, 13 of which can be accessed free at:

http://rnajournal.cshlp.org/content/10/11/1813.full.html\#ref-list-1

Articles cited in:

http://rnajournal.cshlp.org/content/10/11/1813.full.html\#related-urls

License Email Alerting $\begin{aligned} & \text { Receive free email alerts when new articles cite this article - sign up in the box at the } \\ & \text { Service }\end{aligned}$ top right corner of the article or click here.
}

To subscribe to $R N A$ go to:

http://rnajournal.cshlp.org/subscriptions 